\title{
Analyzing Problems Posed by Prospective Teachers Related to Addition and Subtraction Operations with Integers
}

\author{
Cemalettin IŞIK ${ }^{1}$ \\ ${ }^{1}$ Associate Professor, Education Faculty, Erciyes University, Kayseri, Turkey \\ Correspondence: Cemalettin IŞIK, Associate Professor, Department of Mathematics and Science Education, \\ Education Faculty, Erciyes University, Kayseri, Turkey. E-mail: cisik@erciyes.edu.tr
}

Received: April 18, 2018

Accepted: May 6, 2018 Online Published: May 29, 2018

doi:10.5539/hes.v8n3p1

URL: https://doi.org/10.5539/hes.v8n3p1

\begin{abstract}
In this study, it was aimed to analyze the structure of prospective middle school mathematics teachers' problems posed with regard to given symbolic representation including addition and subtraction operations with integers. The study conducted with 96 last grade elementary school mathematics teacher candidates studying in Faculty of Education of Erciyes University in Turkey at the beginning of 2018 years. A Problem Posing Task including five items regarding addition and subtraction operations with integers and semi-structured interview forms were used as data gathering tools. Results indicated that prospective teachers had difficulties in choosing problem types with regard to the given operation structure. Prospective teachers presented less success in problem posing with integers having different signs. Besides, some of the prospective teachers used signs of integers and operations interchangeably and some others multiplied signs of integers and operations, and they gave meaning to the result of this multiplication while they were posing problems.
\end{abstract}

Keywords: addition and subtraction operations with integers, problem posing, prospective mathematics teachers

\section{Introduction}

In mathematics, one of the topics students have difficulties is integers and operations with integers (Hayes \& Stacey, 1999; Kilhamn, 2008). The reason behind this difficulty is epistemological and there are limited natural situations that can be used to represent operations with negative integers. Negative numbers cannot be seen in students' physical world and because of this, it is hard to conceptualize. While positive numbers can be embodied in mind with real objects; about negative numbers, there are not any non-positive objects or object groups in physical world. So, with observing physical world it is not possible to gain informal knowledge (Linchevski \& Williams, 1999; Mc Corkle, 2001).

Studies about integers are grouped generally in two different categories in literature. Some of these studies are focused on difficulties in learning about negative numbers and doing operations with numbers (Hativa \& Cohen, 1995; Vlassis, 2004; Steiner, 2009; Pierson-Bishop, Lamb, Philipp, Whitacre, \& Schappelle, 2014). Other studies regarding integers are about the ways of improving students' understanding of integers. Models used in these studies basically can be categorized in two groups: Neutralization models and number line models. Neutralization models are about negative and positive quantities consisted of concrete objects and number line models emphasized direction meaning of integers (Lytle, 1994). Advocates of these models also claim that they allow students to use the idea of inverse operations and additive inverses by recognizing that one could either take away positives or add negatives to achieve the same result (Semadeni, 1984; Linchevski \& Williams, 1999). Some other researchers, on the other hand, criticized neutralization models due to the fact "they involve rules which are not consistent with the rules of mathematics" (Rousset, 2010; Star \& Nurnberger-Haag, 2011; Vig, Murray, \& Star, 2014). Some subtraction problems necessitate adding additional chips for solving them, this challenges mathematical rules (Vig et al., 2014). In number line models, sign of addition indicates moving towards right direction and sign of subtraction operation indicates moving left direction. "+" sign in front of integers means conserving direction, "-" sign on the other hand symbolizes moving opposite direction. However, some researchers criticize giving meaning to "-" movement while doing addition and subtraction operations on a number line necessitates rules (Nurnberger-Haag, 2007; Star \& Nurnberger-Haag, 2011; Bofferding, 2014).

Textbooks follow an arrangement which is about teaching understanding of integers and operations in integers. In this process there are not concrete pedagogical objects like in teaching natural numbers. For integers, typical 
pedagogical models are number line and neutralization models and teaching with both models have both contributions and obstacles (Vig et al., 2014). For eliminating obstacles, it can be benefitted from metaphors or analogies included in contexts and problems during teaching process. Contexts adapted to real life situations will ease thinking ways about integers or conceptual models of integers and it will help in linking up the things students learnt and real life practices (Altıparmak \& Özdoğan, 2010). In reality, we cannot see a negative number of things. However, we can think of debt as a negative amount of money and assets as a positive amount of money. These concepts do exist in daily life and should be related to integers (Steiner, 2009). Munoz (2010) reported that informal information acquired during students' daily lives has a significant position in their learning integers process. According to Gallardo (2002), if negative numbers and operations including them are restricted only by mathematical symbols, establishing concrete meanings of words in problems becomes harder. The researcher reported that students are able to imagine 20 meters below the sea level or being 20 meters behind while (-20) means nothing to them. According to Swanson (2010), by storytelling contexts and adapting them to real life is a chance for students to develop language skills. Thus, by relating real life and mathematical language will enhance conceptual understanding about integers. On the other hand, children construct new knowledge with previous knowledge and by this way using problems with meaningful contexts will decrease the probability of developing misconceptions by students (Pratt \& Simpson, 2004).

Students' experiences at home, school and environment present contexts for valuable mathematical tasks. Researchers indicate the importance of choosing appropriate context (Heuvel-Panhuizen, 2003; Heiron, 2003). While choosing contexts, it should be considered that they should be "real" and at the same time they should be related with children's culture and environments. Contexts should enhance new strategies and concepts (Barton, 1996) and problems constituted with contexts should reflect rightly necessary operation for solution. Due to this, both teachers and prospective teachers should be careful about the problems they used during their lessons or the problems they posed during teaching integers. However, it is not easy duty to pose problems which are appropriate for operations in integers. Ma (1999) mentioned that teachers found difficult to pose problems about real life issues with respect to given symbolic addition and subtraction operations. Steiner (2009) indicated that only 20 of 79 class teachers could pose problems appropriate to real life issues with respect to given $(-5)+3$ operation. In this study it was aimed to analyze the structure of prospective middle school mathematics teachers' problems posed with regard to given symbolic representation including addition and subtraction with integers.

\section{Method}

\subsection{Participants}

This is a case study and was conducted at the beginning of 2018 years with 96 prospective teachers (59 females, 37 males) studying at the last grade of Elementary Mathematics Teaching Program provided by Education Faculty of Erciyes University in Turkey. 102 prospective teachers in total studying at the last grade. They were informed about the study before the study was started. As a result, 96 prospective teachers agreed to participate in the study voluntarily. Semi-structured interviews were conducted with 16 prospective teachers. Interviews were done with participants who posed problems that were not appropriate to items in Problem Posing Task [PPT]. Semi-structured interviews were conducted to find the reasons for the errors in posed problems. Prospective teachers $[\mathrm{PT}]$, who were interviewed, were coded by PT1, PT2, ..., PT16 representing the prospective teacher while the researcher $[R]$, who conducted the interview, was coded by $R$.

Elementary school (middle school) mathematics teachers in Turkey graduate from four-year undergraduate program of education faculties of universities. This program focuses on how mathematics can be taught to 11-15 years-old student groups (grade $5^{\text {th }}$ to grade $8^{\text {th }}$ ). The elementary mathematics teaching program has classes in general culture, knowledge in the field of mathematics and pedagogy. Besides in-field lessons, prospective teachers take mathematics teaching methods lessons in their third year. In this lesson, there are theoretical and practical activities aimed at basic elementary mathematical concepts including operations with integers. Furthermore, in the last year of the mathematics teaching program, prospective teachers participate in teaching activities in schools where there are 11-15 years-old student groups. Prospective teachers practice in middle schools within "Teaching Practice" course which lasts 14 weeks and includes 6 hours practice for each week. This process includes activities like preparing lesson plan, practicing this plan under the control of supervisor teacher in middle schools, evaluation of this practice by teacher in middle school, academician, and prospective teacher himself, and in accordance with these evaluations necessary corrections are done and practices are done again in middle schools.

\subsection{Data Collecting and Analyzing}

PPT composed of 5 items containing addition and subtraction operations with integers and semi-structured 
interviews were used as data collection tool in the study. PPT contains one item for each of addition and subtraction operations of two negative integers, one item for each of addition and subtraction operations of one positive and one negative integers and finally, subtracting of a positive integer from a negative integer. Task items were restricted by the 5 items prepared for such type of occasions. In the pilot study including 24 prospective teachers, each item of PPT was prepared via numeric values. However, the prospective teachers stated that the given numeric values restricted them in posing problems related to daily life. Restriction related to numeric values was removed because it was aimed in the study to determine how prospective teachers attributed meanings to numbers and signs of operations in problem posing. Each item taking place in PPT was presented with a symbolic representation in which letters were used instead of numbers. Thus, the prospective teachers were made free in specifying numbers high or low as much as they wish in the process of problem posing relating to daily life. Table 1 shows items taking place in PPT and their corresponding features.

Table 1. Items taking place in PPT and their corresponding features

\begin{tabular}{ll}
\hline Items & Features \\
\hline$(-a)+(-b)=?$ & Adding two negative integers \\
$(+a)+(-b)=?$ & Adding a positive integer and negative integer \\
$(-a)-(-b)=?$ & Subtracting two negative integers \\
$(+a)-(-b)=?$ & Subtracting a negative integer away from a positive integer \\
$(-a)-(+b)=?$ & Subtracting a positive integer away from a negative integer \\
\hline
\end{tabular}

Prospective teachers were asked to pose a problem relating to daily life for each item taking place in PPT provided that the problem can be solved through the given operation (its solution requires this operation). The posed problems were divided into classes like separate, compare, join and part-part-whole according to the meanings attributed to the operations taking place in symbolic representations. Researchers categorized addition and subtraction problems in natural numbers according to their relations involved in problems as; join, separate, part-part-whole and compare (Carpenter \& Moser, 1983; Carpenter, Fennema, Franke, Levi \& Empson, 1999; Gutstein \& Romberg, 1995; Van de Walle, 2004). In join type problems, there are three types of quantities as beginning quantity, change quantity and final quantity. While addition of change quantity and beginning quantity constitutes join, separation of change quantity and beginning quantity constitutes separate type of problems. Part-part-whole problem involves combination of two parts constituting a whole. Compare problems involve comparison of two quantities. Actually, third quantity is not available, it is the difference of two quantities.

\section{Results}

\subsection{Findings about Addition of Two Negative Integers}

The prospective teachers posed 94 problems in total for the operation of $(-a)+(-b)=$ ?. Two prospective teachers did not answer the question. Table 2 shows the distribution of the posed problems according to the categories.

Table 2. Distribution of the posed problems for the operation of $(-a)+(-b)=$ ?

\begin{tabular}{lc}
\hline Categories & $\mathrm{f}(\%)$ \\
\hline Join & $72(76.6)$ \\
Part-part-whole & $22(23.4)$ \\
Total & $94(100)$ \\
\hline
\end{tabular}

According to Table 2, 94 of the problems posed about the addition of two negative integers are appropriate to given operation. Prospective teachers are found to be successful in appropriate problem posing with regard to addition in two negative integers. $76.6 \%$ of the problems posed by the prospective teachers take place in join category. The prospective teachers attribute same meanings to $(-a)$ and (-b). The prospective teachers posed problems questioning the result by applying a change equaling to (-b) to (-a) One of the prospective teachers provided an answer seen below included in join category.

Credit card debt of Mr. Ahmet is 1200 TL. An interest equaling to 80 TL is accrued on the debt because he has failed to pay his debt on time. Express how much total debt of Mr. Ahmet.

In the problem phrase, (-a) means credit card debt of $1200 \mathrm{TL}$ while (-b) represents the accrued interest, of 80 Turkish Liras (TL). Thus, the operation of $(-1200)+(-80)$ is required to find the total debt. The resulting -1280 represents the total debt. 
$23.4 \%$ of the problems posed by the prospective teachers take place in part-part-whole category. In this category, the prospective teachers have considered (-a) and (-b) as parts of a whole and posed problems questioning the whole. A prospective teacher's answer classified in this category is seen below:

Ali's debt to greengrocer is 80 Turkish Liras and to butcher is 120 Turkish Liras. Express the total debt of Ali including those to greengrocer and butcher.

In the problem posed by the prospective teacher, (-a) and (-b) represent the amounts indebted to greengrocer and butcher respectively. In addition, the prospective teacher has questioned total amount indebted to greengrocer and butcher and aimed to establish a meaning suitable for addition operation. The problem, as is, is suitable for addition operation of $(-80)+(-120)$.

\subsection{Findings about Addition of a Positive Integer with a Negative Integer}

The prospective teachers posed 94 problems in total relating to the operation of $(+a)+(-b)=$ ? while two prospective teachers did not respond the item. Distribution of the posed problems according to the categories is seen in Table 3.

Table 3. Distribution of the posed problems for the operation of $(+a)+(-b)=$ ?

\begin{tabular}{lc}
\hline Categories & $\mathrm{f}(\%)$ \\
\hline Join & $49(52.1)$ \\
Separate & $45(47.9)$ \\
Total & $94(100)$ \\
\hline
\end{tabular}

According to Table 3, the problems posed about addition of a positive with a negative integer are in join and separate categories. Problems under join category are appropriate to the given operation, whereas problems under separate category (except 7 problems) are not appropriate to the operation given. According to table 2 and table 3, prospective teachers had more difficulty in posing problems about addition of a positive integer and a negative integer problem than addition of two negative integers. $52.1 \%$ of the problems posed by the prospective teachers take place in join category. The prospective teachers made the quantity including $(+a)$ units subject to a change equaling to (-b) units to question the result. Besides, in all posed problems under this category involve $|a|>$ $|\mathrm{b}|$. A prospective teacher's answer in this category is seen below:

Elif gets on a lift at the ground floor and goes 7 floors up and then, 3 floors down. Thus, say the floor at which Elif exists.

In the posed problem, according to the prospective teacher, (+a) represents elevating 7 floors upward while (-b) shows the movement 3 floors downward from $7^{\text {th }}$ floor. Because the question is which floor Elif exists at, the solution requires the operation of $(+7)+(-3)$. However, $47.9 \%$ of the posed problems take place in separate category although the relevant operation is addition. Only 7 prospective teachers, who chose this category, preferred direction concept in problems posed. 7 of them used temperature and elevator movements as their contexts. In other 38 problems, in spite of direction concept, generally they used concrete objects, money or expense contexts. In this category, the prospective teachers posed problems recalling subtraction operation with natural numbers. The answer of PT3 considered in separate category is seen below as an example:

Aysun buys airtime to use on her mobile phone for 40 TL. How much does she have left if she spends 20 of it?

The interview with PT3 is seen below:

$\mathrm{R}: \quad$ Explain how did you pose the problem?

PT3: I assumed the existing airtime as positive and the spent airtime as negative. Airtime included 40 Turkish Liras (TL) and I assumed 20 of it as spent. Then, I posed this problem.

R: How do you solve this problem?

PT3: $\quad 40+(-20)=20$

R: $\quad$ Explain how you expressed addition operation existing in your solution in the problem.

PT3: There were 40 airtimes at the beginning and 20 of them were spent. Gathering them yields $(+40)+$ (-20) in my opinion.

$\mathrm{R}: \quad$ Doesn't the phrase of "if Aysun spends 20 airtimes" require addition operation?

PT3: In fact, (...) I think, there is no addition. I asked the rest and this means subtraction. 
R: What may be the reason for it?

PT3: $\quad$ First of all, I aimed to attribute meaning to numbers. However, I see now that I ignored it. In fact, the operation's sign is plus and that of b number is minus. They yield the result as minus. Thus, my question was how many airtimes she has left. However, it does not fit when it is compared with the problem.

(+a) in the given operation is represented by 40 airtimes in the problem phrase written by the prospective teacher. Then, he continued to write the phrase for his problem by saying that 20 airtimes are spent. The problem is solved with the operation $40-20$. The prospective teacher suggests subtraction operation with the phrase of "how many airtimes does she have left?" whereas sign of the operation is plus while that of the number is minus. It is seen that the prospective teacher has posed the problem based on the minus plus resulting from multiplication of plus and minus signs. As a result, the problem posed in a way recalling a subtraction operation with natural numbers requiring 20 units taken (subtracted) away from 40 instead of addition of two numbers that is one of them is positive while the other one is negative. Thus, 38 problems don't satisfy the given operation.

\subsection{Findings about Subtraction of Two Negative Integers}

The prospective teachers posed 87 problems related to the operation of $(-a)-(-b)=$ ? while nine prospective teachers did not answered the item. Distribution of the posed problems according to the categories is seen in Table 4.

Table 4. Distribution of the posed problems for the operation of $(-a)-(-b)=$ ?

\begin{tabular}{lc}
\hline Categories & $\mathrm{f}(\%)$ \\
\hline Separate & $38(43.7)$ \\
Join & $30(34.5)$ \\
Compare & $19(21.8)$ \\
Total & $87(100)$ \\
\hline
\end{tabular}

According to Table 4, there are problems posed about subtraction of two negative integers and these are in three categories. 57 of the problems $(65.5 \%)$ under the separate and compare categories are appropriate to the structure of the given operation. When Table 2 and Table 4 are compared, prospective teachers had more difficulty in posing problem with regard to subtraction of two negative integers problems than posing problem with regard to addition of two negative integers. On the other hand, 30 of the problems $(34.5 \%)$ under the join category are not appropriate to the structure of the operation. $43.7 \%$ of the problems posed by the prospective teachers take place in separate category. Prospective teachers used a loan of money context in their problem posed under this category and absolute value of a is greater than absolute value of $b$ in their problems $(|a|>|b|)$. A prospective teacher's answer classified in this category is seen below:

Ayşe buys a pair of shoes at a price of 80 TL according to an installment plan. What is the rest amount indebted after the first installment of 20 TL is paid?

In the posed problem, the prospective teacher has assigned the price of the goods to (-a) and the paid first installment, $20 \mathrm{TL}$, to (-b). Because the question root of the problem asks the rest debt amount, the solution requires the operation of $(-80)-(-20)=$ ?. Thus, the prospective teacher posed a problem classified in separate category by subtracting $20 \mathrm{TL}$ away from $80 \mathrm{TL}$ satisfying the given operation. Also, $21.8 \%$ of the problems posed by the prospective teachers take place in compare category. In this category, the prospective teachers compared two numbers to attribute a meaning to sign of the operation. A prospective teacher's answer classified in this category is seen below:

Last night, average weather temperature was measured as -8 Celcius degrees in Kayseri and as -2 Celcius degrees in Ankara. Thus, how many Celcius degrees Kayseri was colder than Ankara last night?

In the posed problem, according to the prospective teacher, (-a) stands for average weather temperature in Kayseri and (-b) for that in Ankara. Because the question root of the problem asks how many degrees Kayseri was colder than Ankara last night, the solution requires the operation of $(-8)-(-2)$. Thus, the prospective teacher has established suitable meanings for signs of number and operation in this problem existing in compare category.

However, $34.5 \%$ of the problems posed by the prospective teachers take place in join category. It was observed that problems requiring addition operation instead of subtraction operation were posed while verbal expressions could not be established satisfying sign of (-b). Two prospective teachers' answers classified in join category are 
seen below:

A submarine navigating $500 \mathrm{~m}$ below the sea level goes $100 \mathrm{~m}$ up. What the position of the submarine versus the sea level.

I owed to Ali 8 liras. Ali owed me 2 liras. Thus, how much money I owed to Ali?

In the written first problem, the prospective teacher assigns that the submarine is $500 \mathrm{~m}$ below the sea level to (-a). However; it is not clear enough that how he considers -(-b) in afterwards of the problem phrase. The prospective teacher was interviewed and asked to explain how he has posed the problem. The prospective teacher said that $a$ 's sign is minus. It occurred to me posing a problem based on sea level. Thus, I said that the submarine is assumed $500 \mathrm{~m}$ below the sea level. Then, I thought about its movement upwards 100 meters and finally, questioned the position versus the sea level. Then, during the interview, the prospective teacher was asked how he has associated the expression of -(-b) and the movement upwards a 100 meter. The prospective teacher said that -(-b) involves multiplication of two minus signs and this yields a plus sign, sign of a is minus. Thus, the negative number will be reduced when it is added to the positive number. I assumed that it should go upward because such movement has a positive sign. It is seen the prospective teacher posed the problem based on the fact that multiplication of two minus signs gives a plus sign. A problem was posed by considering + sign resulting from multiplication of two minus signs although it had been asked that a problem would have been posed including subtraction operation with integers. In the second problem, the prospective teacher assigns his debt of 8 liras to Ali to (-a) while (-b) stands for Ali's debt of 2 Turkish Liras to him. However, Ali's debt of 2 Turkish Liras to him is a receivable for him. Thus, this should be represented by $(+b)$ instead of (-b). Thus, the prospective teacher failed to establish the suitable meaning for minus sign in the expression of (-b).

\subsection{Findings about Subtraction of a Negative Integer from a Positive Integer}

The prospective teachers posed 88 problems in total relating to the operation of $(+a)-(-b)=$ ? while eight prospective teachers did not respond to the item. Distribution of the posed problems according to the categories is seen in Table 5.

Table 5. Distribution of the posed problems for the operation of $(+a)-(-b)=$ ?

\begin{tabular}{lc}
\hline Categories & $\mathrm{f}(\%)$ \\
\hline Join & $36(40.9)$ \\
Separate & $28(31.8)$ \\
Compare & $24(27.3)$ \\
Total & $88(100)$ \\
\hline
\end{tabular}

According to Table 5, problems posed about subtraction of a negative integer from a positive integer are under join, separate and compare categories. Problems posed under join and separate categories are not appropriate to the structure of the given operation, whereas problems under compare category are appropriate to it. This rate is just $27.3 \%$. Prospective teachers had more difficulty in this item within 5 situations given. It is seen according to Table 5 that $40.9 \%$ of the problems posed by the prospective teachers take place in join category although the given operation is subtraction. PT7's answer classified in join category is seen below:

Ayşe has 4 play beads. She borrows 3 play beads from Ali. Now, how many play beads does Ayşe have?

The interview with PT7 is seen below:

R: $\quad$ Please inform us about the problem that you have posed.

PT7: The operation's sign is minus and sign of b number is also minus. If we multiply them with each other, the result will be positive. Thus, the result will be higher. Therefore, I assumed that Ayşe has 4 play beads because number of play beads increases at the end and I wrote the problem.

R: $\quad$ Please kindly solve the problem phrase.

PT7: $\quad(+4)-(-3)=(+7)$

R: $\quad$ Explain how you have expressed the subtraction operation in the problem phrase.

PT7: [after thinking for a while] In fact, there is no direct subtraction operation. This result occurred because multiplication of two minus signs was plus. It became as if it is the sum of two numbers. Honestly, I did not review and check the correlation with the operation. If I checked, possibly it would have not occurred like this. Furthermore, subsequence of two minus signs makes problem posing 
harder.

R: Why do you think that it makes problem posing harder?

PT7: Because there are two minus signs, it should be considered it as not of not. Establishing sentences are very hard. Even if you write it, it seems meaningless.

The prospective teacher was asked to pose a problem for the operation of $(+a)-(-b)=$ ? ; however, the problem is solved with the operation of $4+3$ with natural numbers. The number of play beads, 4 , is put in the place of (+a) while (-b) number represents 3 play beads indebted; however, any meaning could not be attributed to the subtraction operation. According to the prospective teacher as understood in the interview, being minus of both of the signs, of the operation and of the number of $b$, makes problem posing harder. The prospective teacher wrote a problem phrase requiring addition operation with natural numbers benefiting from the fact that multiplication of a minus with another minus yields plus.

Another prospective teacher posed a similar problem like "Ayşe has 8 Turkish Liras. She lends 6 Turkish Liras to her friend. How much money does Ayşe have after her friend pays the debt?". The problem is solved with the operation of $8+6$ with natural numbers. Objective of the prospective teacher is to make (-6) represent lending 6 Turkish Liras to a friend. However, because the question is how much money Ayşe has after she receives the sum credited, the received 6 Turkish Liras will not be a debt for Ayşe. Thus, meaning of (-6) is not represented properly. It is also seen that the suitable meaning for the sign of the operation could not be established. Therefore, it may be said that prospective teachers experience troubles in attributing meaning to signs of numbers and operations while they are posing problems and as a result, they pose problems requiring addition operation with natural numbers.

$31.8 \%$ of the problems posed by the prospective teachers take place in separate category. Similarly, meanings attributed by the prospective teachers, who posed problems in this category, to numbers and operation signs carry the problems posed by them to separate problems' category requiring subtraction operation with natural numbers to be solved. PT10's answer classified in this category is seen below:

Ali has 5 TL. How much money does Ali have left if he fulfills his debt equaling to 4 TL?

This prospective teacher was asked to explain how he has posed the problem during the interview. The prospective teacher said that "I decided that if Ali has 5 TL, this may be represented by (+5) and the debt of 4 TL by (-4). Fulfilling the obligation would be subtraction operation to me. The student aimed that (+a) was replaced by $5 \mathrm{TL}$ and (-b) by $4 \mathrm{TL}$ as a debt. Furthermore, fulfilling the obligation means subtraction operation to him. Then, when he was asked to solve the problem during the interview, he wrote the operation of $(+5)-(-4)=$ $(+9)$. Then, when he was asked to associate the result with the question root of the problem and interpret it, the prospective teacher said [after he read the problem] that it seems like he has (+9) TL but his money has increased although it should have decreased. Signs are fulfilled as meaning but the result is not consistent. Then, he said that I focused on attributing meaning to numbers and signs and I thought that establishing phrases corresponding to them would be enough. If I solved to check the problem after I posed it, possibly, I would have been able to avoid this failure. If signs of numbers are $(+5)$ and $(-4)$ and the operation is assumed as subtraction, the solution will be $(+5)-(-4)=(+9)$. However, Ali pays his debt of 4 TL from his 5 TL. Then, he has 1 TL left according to $5-4=1$. The prospective teacher's attempt to attribute the meaning of fulfilling the debt of 4 TL from the existing money to the subtraction operation resulted in subtraction operation with natural numbers. The result of the operation of $(+5)-(-4)=(+9)$ would be meaningful if the prospective teacher assumed allocated $4 \mathrm{TL}$ for the debt beside $5 \mathrm{TL}$ and used subtraction operation in representation of eliminating indebtedness. However, if the existing problem is under consideration, the solution in the form of $(+5)-$ $(-4)=(+9)$ has no relation with the problem.

$27.3 \%$ of the problems posed by the prospective teachers take place in compare category. In this category, the prospective teachers posed problems focused on comparing two numbers to find the difference between them. A prospective teacher's answer classified in this category is seen below:

Weather temperature is measured 5 Celcius degrees during daytime on Monday while it is measured as -8 Celcius degrees at night. Find how many Celcius degrees temperature measured during daytime is higher than that measured at night.

In the posed problem, (+a) stands for weather temperature measured during daytime while (-b) represents that measured at night according to the prospective teacher. The prospective teacher, in the problem phrase established by him, have compared two different measurement results and attributed subtraction meaning to sign of the operation. Thus, the problem satisfies signs of numbers and operation in the symbolic representation and 
its solution requires the operation of $(+5)-(-8)=(+13)$.

\subsection{Findings about Subtraction of a Positive Integer from a Negative Integer}

Prospective teachers posed 86 problems for the operation of $(-a)-(+b)=$ ? while ten prospective teachers did not answer the item. Table 6 shows distribution of the posed problems according to categories.

Table 6. Distribution of the posed problems for the operation of $(-a)-(+b)=$ ?

\begin{tabular}{lc}
\hline Categories & $\mathrm{f}(\%)$ \\
\hline Join & $50(58.1)$ \\
Compare & $36(41.9)$ \\
Total & $86(100)$ \\
\hline
\end{tabular}

According to Table 6, problems posed about subtraction of a positive integer from a negative integer are under join and compare categories. Although it is a subtraction operation, none of the prospective teachers could pose problems appropriate to separate category. Problem statements under join category are not appropriate to the structure of the given operation, whereas, problems posed under compare category are appropriate to it. $58.1 \%$ of the problems posed by the prospective teachers take place in join category although the given operation is subtraction. Answer of PT14 included in this category is seen below:

A fish is swimming $5 \mathrm{~m}$ below the sea level. What will be the last distance between fish and sea level if the fish swims 3 m up from its first position?

The interview with PT14 is seen below:

R: $\quad$ Explain how you have posed the problem.

PT14: I said if the fish swims under the sea level as $5 \mathrm{~m}$ depth. This expression meets (-a). Then, I think about $-(+b)$ it represents fish's movement $3 \mathrm{~m}$ above towards sea level. Thus, I wrote the problem.

R: $\quad$ You mean $-(+b)$ represents fish's movement $3 \mathrm{~m}$ above. Can you explain which phrase satisfies minus sign and which phrase satisfies sign of $b$ number?

PT14: Now this expression means that $3 \mathrm{~m}$ above meets positive sign. Fish's going away meets negative sign.

R: $\quad$ You finished your question as what will be the total distance from sea level? Does your question meet subtraction operation?

PT14: Himm. In the last situation I asked total distance. It necessitates addition operation. Apparently, I posed problem wrongly. In this situation operation is addition. It should go 3 meter above not below. Then, $(-5)+(-3)=(-8)$. I said reverse. Result is right but meanings are different.

In problems posed, (-a) represents fish being $5 \mathrm{~m}$ below the sea level. Prospective teacher has difficulty in giving appropriate to meaning to $-(+\mathrm{b})$ expression. Participant thought that in fish movement $3 \mathrm{~m}$ above expression, $3 \mathrm{~m}$ above means $(+)$ and distance from sea level means (-). None the less, what will be the total distance? question evokes addition operation in spite of subtraction operation. In interview with the prospective teacher s/he confirmed this situation. $3 \mathrm{~m}$ below meets $(-3)$ in this context and problem transformed into $(-5)+(-3)=$ ? operation. None the less, $(-a)-(+b)=$ ? operation is a subtraction operation. In this problem, which is evaluated under join category, the sign of the operation was used as the sign $b$ number.

$41.9 \%$ of the problems posed by the prospective teachers take place in compare category. The prospective teachers, in this category, posed problems comparing two numbers by attributing the meaning, which is opposite of that attributed to $(-\mathrm{a})$ in the operation of $(-a)-(+b)=$, to $(+\mathrm{b})$. A prospective teacher's answer taking place in compare category is seen below:

Parking lot of a shopping mall exists in two floors below the ground floor while cinema takes place in 5 floors above it). Thus, explain the position of parking lot according to cinema.

In the posed problem, (-a) is represented by the position of parking lot according to the shopping mall's ground floor while $(+b)$ stands for the position of cinema according to the shopping mall's ground floor. Because the problem questions the position of parking lot according to cinema, meaning of subtraction has been attributed to sign of the operation. The problem, as is, satisfies signs of numbers and operation in the symbolic representation and its solution requires the operation of $(-2)-(+5)=(-7)$. The result of $(-7)$ obtained from the solution of 
the problem posed by attributing compare meaning indicates that the parking lot takes place 7 floors below the cinema.

\section{Discussion and Conclusion}

In the study, 5 items were provided to the prospective teachers and they were asked to pose problems relating to addition and subtraction operations with integers. Prospective teachers preferred join, part-part-whole and separate categories for problems posed about addition operation and preferred join, separate and compare categories for subtraction operations. When the distribution of categories is considered, generally they chose to pose problems appropriate to join category. While join category is related with addition operation, prospective teachers preferred join category for subtraction operation necessitating problems. About addition with integers, $98 \%$ of the prospective teachers can pose problems. On the other hand, about subtraction with integers 90-92\% of them can pose problems. Based on these findings, it can be said that they had more difficulty in posing problems appropriate to subtraction than addition. Researchers (Lytle, 1994; Gallardo, 2002; Ryan \& Williams 2007; Steiner, 2009) also stated that it is hard for students to understand subtraction in integers. According to Lytle (1994) many of models that were described in the literature had some deficiencies in supporting the subtraction especially when the signs were different. When the findings of this study are considered, it is seen that there is a similar result.

In problem posed by prospective teachers, preferred addition or subtraction structure and the appropriateness of problems' structure with respect to given operation (symbolic representation) are analyzed together. First operation given was $(-a)+(-b)=$ ? for participants to pose addition necessitating problems. It was found that the prospective teachers posed problems in join and part-part-whole categories for the operation of $(-a)+$ $(-b)=$ ?. Join type from these categories were more preferred (\%76.6). It may be said the fact that signs of $(-a)$ and $(-b)$ numbers are same in the given addition operation facilitates verbal expression of $(-a)$ and $(-b)$ in a problem sentence. In problems posed, beginning quantity (-a) and change quantity (-b) were selected and final is related with addition operation. In problems, contexts like a loan of money, fish moving towards more depth below sea level, going down in mines, fall of temperature under 0 degree, a pigboat's movement towards depth were used. When contexts used are considered, problems are coherent with both neutralization model and number line model. Therefore, contexts used together with problems under join category are found to be appropriate to addition of two negative numbers. Furthermore, the prospective teachers posed problems, in part-part-whole category, requiring to find a whole by gathering different numbers or quantities belonging to the said whole. In problems of this category, invoice or a loan of money contexts were used. Prospective teachers thought total payable loan of money as whole, different invoices or different loan of money as parts (for example, Emrah owed 5 TL to Hasan and 3 TL to Ayşe. Find the total debt of Emrah). Therefore, in problems of this category signs of number and operation are reflected rightly, so they are evaluated as appropriate. It can be said that problems of part-part-whole category are coherent with neutralization model and number line model.

Second operation that prospective teachers were asked to pose problem about addition in integers was $(+a)+(-b)=$ ? The prospective teachers posed problems included in join and separate categories for this operation. Although the given operation is addition, the prospective teachers did not pose problems, which might be included in part-part-whole category. $52.1 \%$ of the problems take place in join category. In join category, opposite meaning was attribute to (-b) to the meaning of (+a) Then, problems were posed questioning the result by changing (+a) by a quantity of (-b) units. Moreover, it is found that all the problems posed under this category included $|\mathrm{a}|>|\mathrm{b}|$. The reason of this preference might be because of eliminating the probability of negative result at the end of operation. In posed problems, contexts like increasing / then decreasing temperature, elevator's movement towards up / then down, walking at first in one direction / then walking in other direction were used. Therefore, it can be said that this type of problems appropriates to join category were evaluated structure of operation. Problems posed appropriate to $|\mathrm{a}|>|\mathrm{b}|$ were coherent with both neutralization model and number line model. In addition with integers related problems in textbooks generally use real life examples or counters or number line as concrete models representing solution (Bofferding, 2011; 2014; Stephan \& Akyüz, 2012). (47.9\%) of the posed problems take place in separate category although the given operation is addition. According to Bruno and Martinon (1999), addition and subtraction have the same meaning: Adding is joining, while subtraction is separating or taking away. The two operations have the same meaning. This can be expressed by using double language: "I have $3 \$$ " is equivalent to "I owe $-3 \$$. "I won $2 \$$ " is equivalent to "I lost $-2 \$$ ". Subtraction is equivalent to addition of minuend with its additive inverse (Ulrich, 2012). In problems posed in separate category two different structure was seen. Only 7 prospective teachers preferring this category considered direction concept while posing problems, other 38 prospective teachers missed that integers were 
directional quantities. 7 prospective teachers used temperature and movement with elevator contexts in their problems. One of prospective teachers posed following problem "Imge measured temperature (+7) Celcius degrees at noon. In the evening temperature decreased 5 Celcius degrees. So, what is the degree of temperature in the evening? " In the problem beginning temperature was $(+7)$, changing temperature was $(+5)$ and decreasing of temperature was thought as $(-)$ and operation had this form $(+7)-(+5)$. In the same problem, increasing of problem by 7 Celcius degrees was shown as (+7), decreasing 5 Celcius degrees shown as (-5) and final situation (result) was related with addition and it can be solved with $(+7)+(-5)$ operation. Therefore, 7 problems posed under separate category and including direction concept were evaluated appropriate to given operation. It can be said that 7 problems using temperature and elevator movement contexts are coherent with number line model. None the less, in the other 38 problems prospective teachers generally had tendency to think +(-b) as (-b) and apply this form mechanically. While prospective teachers were posing problems, they constitute only one sign from the sign of number and the sign of operation and they assign meaning to this operation as subtraction operation. Therefore, problems posed were changed into problems necessitating subtraction operation in natural number. In these problems, generally concrete objects, money or spending contexts were used. PT 7 posed following problem "Fatma has 7 marbles, she gives 4 of them to her sister. How many Fatma's marbles are left?" It is clear that this type of problems can be solved with natural numbers without necessitating integers. From this aspect, it is found out that 38 problems posed do not necessitate usage of integers. Steiner (2009) mentioned that only one prospective teacher can pose problems appropriate to $8+(-4)$ operation. However, he stated that 37 prospective teachers posed problems that can be solved with subtraction operation in natural numbers. Similar result was observed for the operation of $(+a)+(-b)=$ ? in this study.

There are three symbolic representations given to prospective teachers for posing problem appropriate to subtraction operation. First of all is $(-a)-(-b)=$ ? operation. The prospective teachers posed problems included in separate, join and compare categories for this operation. The students posed problems in separate category by attributing same type of meanings to (-a) and (-b) in their problem phrases because their signs were same. It is found that among all the problems (43.7\%) prospective teachers posed loan of money as their contexts and they chose absolute value of $a$ is bigger than $b(|a|>|b|)$. This situation might be due to the fact that loan of money context makes easier to pose problems (Otherwise, it might cause logical contradiction to subtract higher loan of money from less loan of money). $|\mathrm{a}|>|\mathrm{b}|$ condition in problems including loan of money context is coherent with neutralization model. It is physically easy to subtract (separate) less (-) counter from higher number of (-) counter. In a reverse situation, for subtracting extra negative counter must be added. It might be due to the fact that prospective teachers preferred using $|a|>|b|$ condition in their problem posed. In case of compare category, they posed problems requiring comparison of two quantities like (-a) and (-b). Contexts used in this category were temperature degrees under zero, positions of fish or pigboat below the sea level, comparison of loan of money situations. In problems using these types of contexts, finding the change was aimed, so, they are coherent with number line model. Number of the problems posed in these two categories accounts for $65.5 \%$ of the problems posed for this operation. Such type of problems can satisfy meaning of the subtraction operation taking place in the given operation. However, approximately one third (34.5\%) of the posed problems do not include meanings suitable for subtraction operation. Especially in this process, prospective teachers posed problems like $(-a)+b$ because they attributed meaning of join to plus sign $(+)$ obtained by multiplication of minus signs of $(-b)$ number and subtraction operation (-). Thus, prospective teachers changed $(-a)-(-b)=$ ? operation into $(-a)+b$ operation and then they posed problems. In problems posed, beginning quantity was $(-a)$, change quantity was $(+b)$, and solution was related with addition operation. In problems posed, fish or pigboats below the sea level, elevator, loan of money and temperature contexts were used. One of the prospective teachers posed following problem as an example for this situation; "In the morning temperature was measured as -8 Celcius degrees. At noon it was increased 6 degrees. What is the last degree of temperature measured at noon?". When problem's structure was analyzed, number sign (-) and operation sign (-) were multiplied, and solution sign $(+)$ was related with the increase of temperature in the problem. Therefore, although given operation was subtraction, problem posed was changed into addition necessitating problem. Thus, this type of problem is not appropriate to subtraction operation. Similar opinions were seen in $(+a)+(-b)=$ ? operation by some prospective teachers while posing problems.

Second operation given for posing problem appropriate to subtraction operation was $(+a)-(-b)=$ ?. $40.9 \%$ of the problems posed for the operation of $(+a)-(-b)=$ ? take place in join category while $31.8 \%$ of the problems posed for it take place in separate category. It was seen in problems taking place in join category that the prospective teachers have focused on + sign obtained by multiplication of sign of the operation and sign of (-b) number. It was seen with the help of interviews also that the prospective teachers assume + as addition operation and turn the given operation into $a+b$. It can be said that prospective teachers were intendency to be 
result oriented approach to operation by applying combined movement mechanically as in $(+a)+(-b)=$ ? and $(-a)-(-b)=$ ? operations. In problems posed, they used generally money related context, but they could not state appropriate meaning to problems which met signs of number and operation. In problems using money context, neutralization model is not appropriate. It is physically hard to separate a quantity constituting of negative counter (-) from a quantity constituting of positive counter (+). Hence, extra neuter counter must be added. However, it is hard to state this situation in a problem sentence. The reason of this difficulty might be due to the fact that in problem posed prospective teachers preferred to pose problems appropriate to addition operation instead of subtraction operation. Therefore, under analyse of these category problems were not appropriate to given operation. Although the given operation is subtraction, the problems classified in separate problems do not meet the given operation. Problems' structure under separate category involve removing or separating beginning quantity (+a) from change quantity (-b). This situation means an increase not like a decrease in natural numbers. Therefore, problems posed under separate category could not meet subtraction operation. In problems posed, prospective teachers constituted meaning for sign of number; they could not constitute sentences appropriate to subtraction operation's separate meaning. For instance, one of prospective teachers posed following question "A bird was flying at an altitude of $5 \mathrm{~m}$. For catching a fish, the bird went $7 \mathrm{~m}$ below from its first position. What was the position of fish before being catched?". In the problem position of bird is represented with (+5), going through below $7 \mathrm{~m}$ is represented with (-7). However, the expression meeting subtraction operation was related with position of the fish. That is to say, prospective teacher could not constitute the expression appropriate to separate meaning of subtraction operation. Although, separate meaning of subtraction is useful in many situations, it is not a useful understanding while studying with signed numbers or vectors (Ulrich, 2012). Problems under compare category involve difference of (+a) and (-b) by giving opposite meanings. Contexts used were altitude, temperature, being debitor-creditor and direction. These contexts are coherent with number line model. Problems' structures under compare category are appropriate to subtraction operation done with signed numbers. The meaning of compare should be emphasized in learning subtraction operation with integers like it has been done in problems relating to subtraction operation with natural numbers (Kullberg, 2007; Ulrich, 2012).

Third operation given to prospective teachers for posing problems appropriate to subtraction operation was $(-a)-(+b)=$ ?. Although it was a subtraction operation, in this operation as in $(+a)-(-b)=$ ? operation problems posed were preferred in uttermost in join category. Although, separate is subtraction category, none of the prospective teachers posed problems appropriate to this category. $58.1 \%$ of the problems posed for the operation of $(-a)-(+b)=$ ? take place in join category while $41.9 \%$ of the problems posed for it take place in compare category. In the join category the prospective teachers replaced operation's sign (-) and (+b) number's sign by each other and turned the expression into addition of two numbers, which are similar in type (both of them are loan of money, height or temperature), in posing problems taking place in this category. Thus, the operation becomes $(-a)+(-b)=$ ? " It may be said that posing such type of problems is easier than posing a problem for the operation of $(-a)-(+b)=$ ? because, according to the findings of the study, join type problems were mostly preferred by the prospective teachers for the operation $(-a)+(-b)=$ ?. One of prospective teachers who used temperature context posed following problem "Cold storage depot's temperature is -9 Celcius degrees. Temperature was decreased by 4 Celcius degrees. What will the last temperature be in Celcius degrees?". When the structure of problem is analyzed, beginning value is (-9), magnitude of change is (decreasing temperature) (-4), the solution is related with addition and it is problem under join category. The solution of problem is done with $(-9)+(-4)$ operation. However, $(-a)-(+b)=$ ? is the expected operation given. Therefore, problem posed is solved addition operation instead of subtraction operation. The reason of prospective teachers' like these thoughts is that it is physically difficult to separate negative quantities from positive quantities. As mentioned difficulty above, subtraction operation done with addition of neuter counter involves neutralization model. It might be thought as prospective teachers did necessary adding for subtraction operation by doing it addition operation. However, problem posed did not meet given operation. It was asked the difference of $(+a)-(-b)=$ ? operation by giving opposite meanings to $(-\mathrm{a})$ and $(+\mathrm{b})$ like in compare category. In problems posed, contexts used were altitude, below the sea level / position of objects above the sea level, temperature degrees under or above zero. Contexts used involve meeting positions on number line and context is appropriate. Posing compare type problems for the operation of $(-a)-(+b)=$ ? are a proper approach for subtraction operation.

As a result, it is found that prospective teachers experienced difficulty in posing problems appropriate to given operation structurally. In problems posed appropriate to addition problems preferred categories and coherence with respect to given operation were higher than subtraction operation. Besides, prospective teachers could not constituted appropriate meaning in problems posed about the signs of number and operations, they used 
interchangeably signs of numbers and operations. This result of the study about the fact that teachers or prospective teachers could not distinguish sign of number and sign of operation from each other is supported by various researchers (Lytle, 1994; Gallardo, 1995; Türnüklü \& Yeşildere, 2007; Harris, 2010). So, this type of errors carried prospective teachers to addition and subtraction operations in natural numbers instead of addition and subtraction operations in integers. On the other hand, prospective teachers had difficulty in choosing appropriate problem category for addition and subtraction operations with respect to given operation. Prospective teachers preferred separate category in problems appropriate to subtraction operation instead of compare category. According to Kilhamn (2011) when integers have been introduced, it becomes necessary to work less with separating situations and more with combine and compare situations. Similarly, Kullberg (2010) mentioned that for understanding negative numbers, the compare meaning is a significant perspective. In the study the ratio of compare category is less and this shows this perspective, which was emphasized by Kilhamn, could not be constructed by prospective teachers. In addition, the obtained results comply with the results saying that achievement of teachers or prospective teachers in posing problems, which associate addition and subtraction operations with daily life experiences, is low (Ma 1999; Steiner 2009). According to these results, it may be said that prospective teachers have a tendency to carry their habits in addition and subtraction operations with natural numbers to those with integers and they do not have conceptual competence enough for addition and subtraction operations with integers. (Fischbein, 1987; Hativa \& Cohen, 1995; Bruno, Espinel \& Martinon, 1997; Bruno \& Martinon, 1999; Gallardo, 2002; Vlassis, 2004; Türnüklü \& Yeşildere, 2007; Harris, 2010).

This study clearly indicates that prospective teachers' skills problem posing relating to addition and subtraction operations with integers should be developed. Findings of the study indicate that prospective mathematics teachers have difficulties in posing problems appropriate to the meaning of addition and subtraction in integers. These difficulties are obstacles to posing problems during the teaching years. For preventing the difficulty of posing problems which is appropriate to given operations, there should be problem posing based learning environments. Data collection instrument problem posing related to addition and subtraction operations with integers via only five items may be considered as restriction of the study. Conducting qualitative and quantitative studies hand by hand with items increased in number may contribute to discovering other possible types of mistakes and may help in generalizing this study. In the study, there are symbolic letters like $a$ and $\mathrm{b}$ in problem posing items and the prospective teachers were allowed to use numbers instead of $a$ and $b$. The reasons of the using numbers they chose instead of $a$ and $\mathrm{b}$ while they are posing problems could also be investigated. Besides, there are 96 prospective teachers in the study; this can also be a limitation. The studies with larger samples could contribute in generalizing the findings of this study. Similarly, increasing the number of prospective teachers' interviews could contribute to understand the reasons why they chose the categories that are not appropriate to the structure of the operations in depth. Moreover, it could be planned problem posing based instructional environments appropriate to addition and subtraction in integers and there could be studies for investigating teachers' and students' change and development about operations in integers.

\section{References}

Altıparmak, K., \& Özdoğan, E. (2010). A study on the teaching of the concept of negative numbers. International Journal of Mathematical Education in Science and Technology, 41(1), 31-47. https://doi.org/10.1080/00207390903189179

Barton, B. (1996). Making sense of ethnomathematics: Ethnomathematics is making sense. Educational Studies in Mathematics, 31, 201-233. https://doi.org/10.1007/BF00143932

Bofferding, L. (2011). Expanding the numerical central conceptual structure: First graders' understanding of integers (Unpublished doctoral dissertation). Standford University, Standford, CA.

Bofferding, L. (2014). Negative integer understanding: Characterizing first graders' mental models. Journal for Research in Mathematics Education, 45(2), 194-245. https://doi.org/10.5951/jresematheduc.45.2.0194

Bruno, A., \& Martinon, A. (1999). The teaching of numerical extensions: the case of negative numbers. International Journal of Mathematical Education in Science \& Technology, 30(6), 789-809. https://doi.org/10.1080/002073999287482

Bruno, A., Espinel, M. C., \& Martinon, A. (1997). Prospective teachers solve additive problems with negative numbers. Focus on Learning Problems in Mathematics, 19(4), 36-55.

Carpenter, T. P., \& Moser, J. M. (1983). The acquisition of addition and subtraction concepts. In R. Lesh \& M. Landau (Eds.), Acquisition of mathematical concepts and processes (pp. 7-44). New York: Academic Press.

Carpenter, T. P., Fennema, E., Franke, M. L., Levi, L., \& Empson, S. B. (1999). Children's mathematics: 
Cognitively guided instruction. Portsmouth, NH: Heinemann.

Fischbein, E. (1987). Intuition in science and mathematics: An educational approach. Dordrecht, Holland: D. Reidel Publishing.

Gallardo, A. (1995). Negative numbers in the teaching of arithmetic. In D. Owens, M. Reeds \& G. Millsaps (Eds.), Proceedings of the 17th Annual Meeting for the Psychology of Mathematics Education (North America Chapter) (Vol. 1, pp. 158-163). Ohio, USA: ERIC Clearinghouse for Science, Mathematics and Environmental Education.

Gallardo, A. (2002). The extension of the natural-number domain to the integers in the transition from arithmetic to algebra. Educational Studies in Mathematics, 49(2), 171-192. https://doi.org/10.1023/A:1016210906658

Gutstein, E., \& Romberg, T.A. (1995). Teaching children to add and subtract. Journal of Mathematical Behavior, 14, 283-324. https://doi.org/10.1016/0732-3123(95)90012-8

Harris, S. J. (2010). The relationship between teacher pedagogical content knowledge and student understanding of integer operations (Unpublished doctoral dissertation). The University of Texas at Austin.

Hativa, N., \& Cohen, D. (1995). Self-learning of negative number concepts by lower division elementary students through solving computer-provided numerical problems. Educational Studies in Mathematics, 28(4), 401-431. https://doi.org/10.1007/BF01274081

Hayes, B., \& Stacey, K. (1999, July). Teaching negative number using integer tiles. In Proceedings of the 22nd annual conference of the mathematics education research group of Australasia (MERGA), Adelaide, Australia.

Heiron, A. (2003). The significance of empirical research for teachers of mathematics using a context to teach negative numbers, MSc Mathematical Education/NQT Certificate of Professional Studies.

Heuvel-Panhuizen, M. (2003). The didactical use of models in realistic mathematics education: An example from a longitudinal trajectory on percentage. Educational Studies in Mathematics, 54(1), 9-35. https://doi.org/10.1023/B:EDUC.0000005212.03219.dc

Kilhamn, C. (2008, January). Making sense of negative numbers through metaphorical reasoning. Paper presented at the conference Madif 6, Stockholm, Sweden. Retrieved from www.mai.liu.se/SMDF/madif6/Kilhamn.pdf.

Kilhamn, C. (2011). Making sense of negative numbers (Unpublished doctoral dissertation). University of Gotenburg, Faculty of Education, Sweden. Retrieved from https://gupea.ub.gu.se/handle/2077/24151?locale=en

Kullberg, A. (2007, 7-9 December). From learning study to design study. Paper presented at EARLI SIG 9 Biennial Workshop, University of Hong Kong.

Kullberg, A. (2010). What is taught and what is learned: Professional insights gained and shared by teachers of mathematics (Unpublished doctoral dissertation). Acta Universitatis Gothoburgensis, Göteborg, Sweden.

Linchevski, L., \& Williams, J. (1999). Using intuition from everyday life in "filling" the gap in children's extension of their number concept to include the negative numbers. Educational Studies in Mathematics, 39, 131-147. https://doi.org/10.1023/A:1003726317920

Lytle, P. (1994). Investigation of a Model Based on the Neutralization of Opposites to Teach Integer Addition and Subtraction. In J. P. da Ponte \& J. F. Matos (Eds.), Proceedings of the 18th international conference for the psychology of mathematics education (Vol. III, pp. 192-199). Lisbon: University of Lisbon.

Ma, L. (1999). Knowing and teaching elementary mathematics: Teachers' understanding of fundamental mathematics in China and the United States. Erlbaum, Mahwah, NJ.

Mc Corkle, K. (2001). Relational and instrumental learning when teaching the addition and subtraction of positive and negative integers (Unpublished master's thesis). California State University, USA.

Munoz, L. (2010). Teaching Strategies for Integers and Operations. Arizona Teacher Institute Action Research Project Report. Retrieved from http://math.arizona.edu/ ime/ATI/Action\%20Research/C1_ARFinal_Munoz.pdf

Nurnberger-Haag, J. (2007). Integers made easy: Just walk it off. Mathematics Teaching in the Middle School, 13(2), 118-121.

Pierson-Bishop, J., Lamb, L. L., Philipp, R. A., Whitacre, I., \& Schappelle, B. P. (2014). Using order to reason 
about negative numbers: the case of violet. Educational Studies of Mathematics, 86(1), 39-59. https://doi.org/10.1007/s10649-013-9519-x

Pratt, D., \& Simpson, A. (2004). McDonald's vs father christmas. Australian Primary Mathematics Classroom, 9(3), 4-9. Retrieved from https://files.eric.ed.gov/fulltext/EJ793890.pdf

Rousset. (2010). Epistemic fidelity of didactical models for the teaching of negative numbers. Retrieved from http://studylib.net/doc/7971524/epistemic-fidelity-of-didactical-modelsfor-the-teaching-of-negative-numbers

Ryan, J., \& Williams, J. (2007). Children's mathematics 4-15: Learning from errors and misconceptions. Maidenhead: Open University Press.

Semadeni, Z. (1984). A principle of concretization permanence for the formation of arithmetical concepts. Educational Studies in Mathematics, 15, 379-395. https://doi.org/10.1007/BF00311113

Star, J., \& Nurnberger-Haag, J. (2011). Toward a research agenda on mathematical models. Paper presented at the Annual Meeting of the American Educational Research Association, New Orleans, LA.

Steiner, C. J. (2009). A study of pre-service elementary teachers' conceptual understanding of integers (Unpublished doctoral dissertation). Kent State University College and Graduate School of Education, US.

Stephan, M., \& Akyüz, D. (2012). A proposed instructional theory for integer addition and subtraction. Journal for Research in Mathematics Education, 43(4), 428-464. https://doi.org/10.5951/jresematheduc.43.4.0428

Swanson, P. E. (2010). The intersection of language and mathematics. Mathematics Teaching in the Middle School, 15(9), 516-523.

Türnüklü, E. B., \& Yeşildere, S. (2007). The pedagogical content knowledge in mathematics: Pre-service primary mathematics teachers' perspectives in Turkey. Issues in the Undergraduate Mathematics Preparation of School Teachers, 1, 1-13.

Ulrich, C. (2012). The addition and subtraction of signed quantities. In R. L. Mayes, \& L. L. Hatfield (Eds.), Quantitative reasoning and mathematical modeling: A driver for STEM integrated education and teaching in context (pp. 127-141). Univeristy of Wyoming, Laramie, Wyoming. Retrieved from http://www.uwyo.edu/wisdome/_files/documents/ulrich.pdf

Van de Walle, J. A. (2004). Elementary and middle school mathematics: Teaching developmentally (5th ed.). Boston, MA: Pearson.

Vig, R., Murray, E., \& Star, J. R. (2014). Model breaking points conceptualized. Educational Psychology Review, 26(1), 73-90. https://doi.org/10.1007/s10648-014-9254-6

Vlassis, J. (2004). Making sense of the minus sign or becoming flexible in "negativity". Learning and Instruction, 14(5), 469-484. https://doi.org/10.1016/j.learninstruc.2004.06.012

\section{Copyrights}

Copyright for this article is retained by the author(s), with first publication rights granted to the journal.

This is an open-access article distributed under the terms and conditions of the Creative Commons Attribution license (http://creativecommons.org/licenses/by/4.0/). 